\title{
Temperature distribution of fluids in a two-section two-phase closed thermosyphon wellbore
}

\author{
Zhang Yufeng ${ }^{1 *}$, Zhao Lun ${ }^{1}$, Fan Zifei ${ }^{1}$, Wu Xiaodong ${ }^{2}$, Fu Libing ${ }^{1,3}$, Xu \\ Bifeng $^{1}$, Kong Fanshun ${ }^{4}$ and Jiang Shengdong ${ }^{5}$ \\ ${ }^{1}$ Research Institute of Petroleum Exploration \& Development, Beijing 100083, China \\ ${ }^{2}$ MOE Key Laboratory of Petroleum Engineering, China University of Petroleum, Beijing 102249, China \\ ${ }^{3}$ School of Energy Resources, China University of Geosciences, Beijing 100083, China \\ ${ }^{4}$ Exploration and Development Research Institute, Petrochina Daqing Oilfield Company, Daqing, Heilongjiang 163000, \\ China \\ ${ }^{5}$ Northeast Petroleum University, Daqing, Heilongjiang 163318, China
}

(C) China University of Petroleum (Beijing) and Springer-Verlag Berlin Heidelberg 2014

\begin{abstract}
Compared with a conventional single section two-phase closed thermosyphon (TPCT) wellbore, a two-section TPCT wellbore has better heat transfer performance, which may improve the temperature distribution of fluid in wellbores, increase the temperature of fluid in wellheads and even more effectively reduce the failure rate of conventional TPCT wellbores. Heat transfer performance of two-section TPCT wellbores is affected by working medium, combination mode and oil flow rate. Different working media are introduced into the upper and lower TPCTs, which may achieve a better match between the working medium and the temperature field in the wellbores. Interdependence exists between the combination mode and the flow rate of the oil, which affects the heat transfer performance of a two-section TPCT wellbore. The experimental results show that a two-section TPCT wellbore, with equal upper and lower TPCTs respectively filled with Freon and methanol, has the best heat transfer performance when the oil flow rate is $200 \mathrm{~L} / \mathrm{h}$.
\end{abstract}

Key words: Two-section two-phase closed thermosyphon, temperature distribution, combination mode, heat transfer performance

\section{Introduction}

The two-phase closed thermosyphon (TPCT, also known as a gravity-assisted heat pipe) is an effective heat transfer device with a simple structure (Sobhan et al, 2007; Khandekar et al, 2008; Paramatthanuwat et al, 2010; Rahimi et al, 2010). High heat transfer performance is achieved by phase transition of the working medium. After evacuating, a predetermined amount of the working medium is introduced into the vacuum cavity in the TPCT. The TPCT transfers heat by the working medium absorbing the heat from the oil in the lower part (absorbing section), and releasing the heat to the oil in the upper part (releasing section) (Jouhara and Meskimmon, 2010; Khamis et al, 2010; Huminic et al, 2011; Shanbedi et al, 2012). Because of its low cost, stable operation and high heat transfer performance, this technology is widely used (Misheck et al, 2006; Fan et al, 2007; Jouhara et al, 2009),

*Corresponding author. email: zhangyufeng-hw@petrochina.com.cn Received December 23, 2012 in applications such as spacecraft thermal control, cooling of electronic components, energy and chemical industry, heat recovery, air-conditioning cooling, solar energy conversion systems, civil heating, geothermal utilization, construction industry, etc (Jaehnig and Isaksson, 2006; Yau, 2006; Pridasawas and Lundqvist, 2008; Jouhara, 2009; Jouhara and Robinson, 2009; Singh et al, 2011). Research on the TPCT to improve the temperature distribution in wellbores has been conducted in China. The requirements for technological and working parameters for TPCTs used in wellbores are not as high as those used in spacecraft thermal control, cooling of electronic components, etc. In practical oilfield applications, thermal and chemical methods are commonly used to reduce the viscosity of crude oil in wellbores, these methods are usually accompanied by tremendous wastage of energy and postprocessing of produced fluids. The TPCT technology may overcome these above disadvantages and improve the temperature distribution of fluids in wellbores (Tian and Finger, 2000; Shi and Homes, 2003; Cazarez-Candia and Vásquez-Cruz, 2005; Wang and Zhao, 2011), reduce heat loss of the wellbore fluid (Aljundi, 2009; Behrooz and Ahad, 
2010), increase the fluid temperature and thus reduce the viscosity of fluids in the wellhead.

The available research shows that best match relationship exists between the working medium and the inlet temperature of the oil (Wu et al, 2008; Zhang et al, 2010; 2011). However, the conventional TPCT used in wellbores is a single extralong heat pipe with a long cavity filled with the same type of working medium. The same working medium cannot suitable for a wide range of temperatures. So, the conventional TPCT in wellbores cannot achieve optimal results. At the same time, the conventional TPCT failure in wellbores is likely to happen because of the seal failure of the long cavity. Therefore, it is necessary to improve the conventional TPCT and overcome the existing disadvantages.

Based on the above analysis, the authors propose the conception of combined two-phase closed thermosyphons. What's more, taking two-section TPCT (including two independent TPCT units) as an example, the temperature distribution and sensitive factors are analyzed based on experiments and theoretical calculation.

\section{Experimental}

\subsection{Experimental apparatus and test procedure}

Fig. 1 shows a schematic of a two-section TPCT wellbore for simulating temperature distribution of fluid flow, which was improved with respect to the one reported by Zhang et al (2010) in the following way. First, the most interior vacuum cavity was divided into two TPCTs, the upper and lower TPCTs, equal in length. Second, an evacuation valve was installed at the bottom of the apparatus, then the lower TPCT would be evacuated and the working medium would be added to the lower TPCT.

The experimental procedure is as follows:

1) The oil was heated to the desired temperature.

2) Operating conditions of the thermocouples and pressure sensors were examined.

3) Cooling water circulation system was operated and the water flow rate was adjusted to $300 \mathrm{~L} / \mathrm{h}$.

4) The upper and lower TPCT cavities were evacuated to $80 \mathrm{kPa}$.

5) The designed working media were charged into the evacuated cavities.

6) The oil circulation system was operated and the oil flow rate was adjusted to the desired value.

7) The temperature and pressure values of all test points were recorded after the system was running smoothly.

\subsection{Experimental materials}

The oil was intermediate base oil, which was a mixture of paraffinic base oil and naphthenic base oil.

The working media, determined from the previous

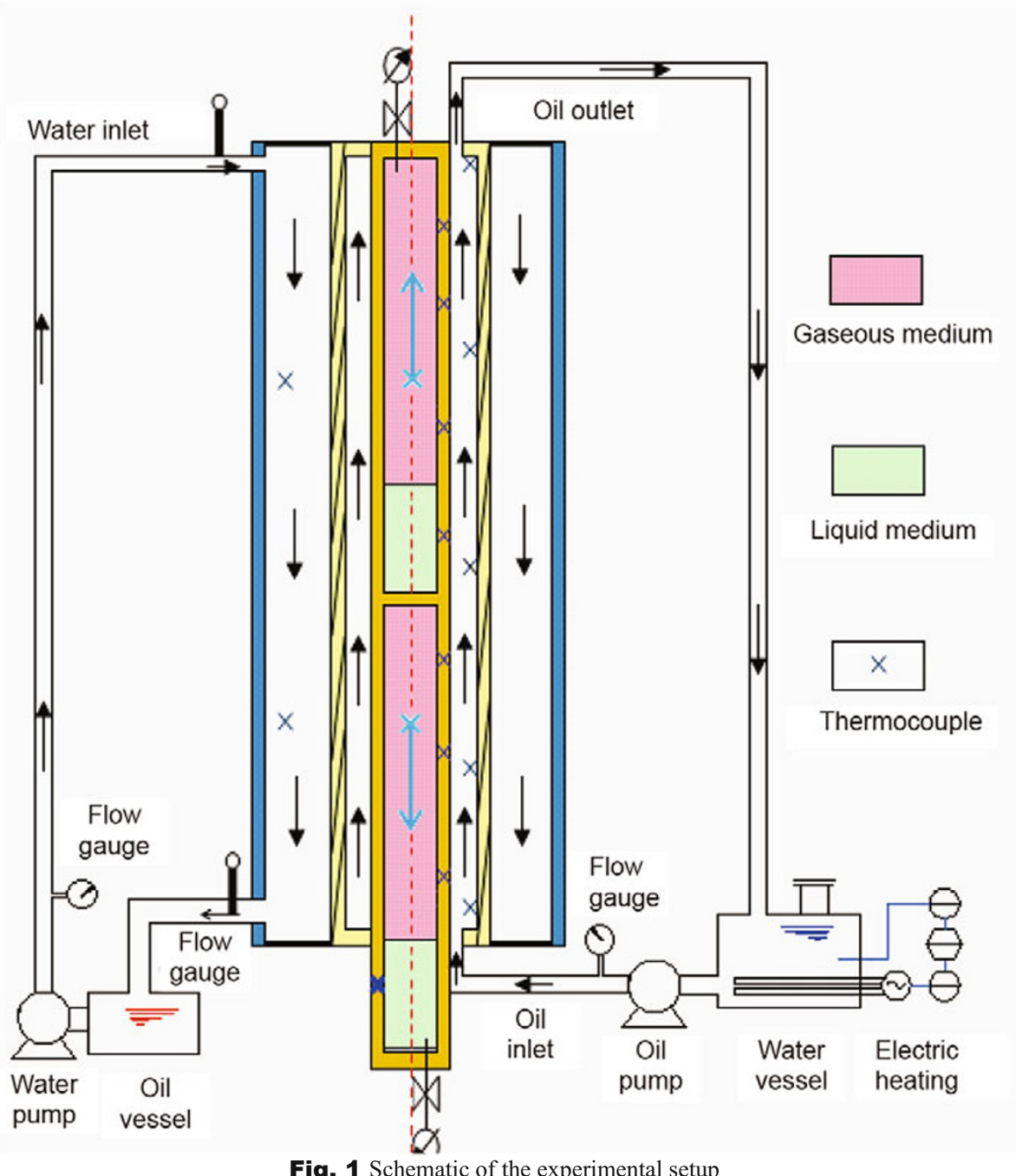

Fig. 1 Schematic of the experimental setup 
research (Zhang et al, 2007; 2010), were respectively Freon and methanol when the inlet temperature of the oil were 50 and $70{ }^{\circ} \mathrm{C}$.

The cooling liquid used in experiments was tap water, with a flow rate of $300 \mathrm{~L} / \mathrm{h}$ at room temperature.

\section{Experimental results and discussion}

In the paper, the experimental data on the conventional wellbores and conventional TPCT wellbores were adapted from previous research (Zhang et al, 2007; 2010).

In order to investigate the performance of two-section TPCT wellbores, a series of tests were carried out and the experimental conditions are listed in Table 1. Figs. 2 and 3 show temperature distributions in different wellbores. In conventional TPCT experiments, the working media were respectively Freon and methanol when the inlet temperature of the oil was 50 and $70{ }^{\circ} \mathrm{C}$. The experimental results show that in the two-section TPCT-F (two-section TPCT filled with Freon) and two-section TPCT-M (two-section TPCT filled with methanol) wellbores the outlet temperatures of the oil increased by 6.5 and $9.2{ }^{\circ} \mathrm{C}$, respectively, compared with the conventional TPCT wellbores. Therefore, the two-section TPCT, whether two-section TPCT-F or two-section TPCT-M wellbores, had better heat transfer performance than the conventional TPCT wellbores.

Table 1 Experimental conditions of heat transfer performance

\begin{tabular}{|c|c|c|c|c|c|c|c|}
\hline \multirow[b]{2}{*}{ Wellbore } & \multicolumn{2}{|c|}{ Working medium } & \multicolumn{2}{|c|}{ Cooling water } & \multicolumn{2}{|c|}{ Oil } & \multirow[b]{2}{*}{$\begin{array}{l}\text { Vacuum degree } \\
\mathrm{kPa}\end{array}$} \\
\hline & Type & $\begin{array}{c}\text { Filling ratio } \\
\%\end{array}$ & $\begin{array}{l}\text { Temperature } \\
{ }^{\circ} \mathrm{C}\end{array}$ & $\begin{array}{c}\text { Flow rate } \\
\mathrm{L} / \mathrm{h}\end{array}$ & $\begin{array}{l}\text { Temperature } \\
{ }^{\circ} \mathrm{C}\end{array}$ & $\begin{array}{c}\text { Flow rate } \\
\mathrm{L} / \mathrm{h}\end{array}$ & \\
\hline Conventional & - & - & - & - & - & - & - \\
\hline Conventional TPCT-F & Freon & 15 & Room temperature & 300 & 50 & 200 & 80 \\
\hline Conventional TPCT-M & Methanol & 15 & Room temperature & 300 & 70 & 200 & 80 \\
\hline Two-section TPCT-F & $\begin{array}{c}\text { Freon (upper and } \\
\text { low TPCTs) }\end{array}$ & 15 & Room temperature & 300 & 50 & 200 & 80 \\
\hline Two-section TPCT-M & $\begin{array}{c}\text { Methanol (upper and } \\
\text { low TPCTs) }\end{array}$ & 15 & Room temperature & 300 & 70 & 200 & 80 \\
\hline
\end{tabular}

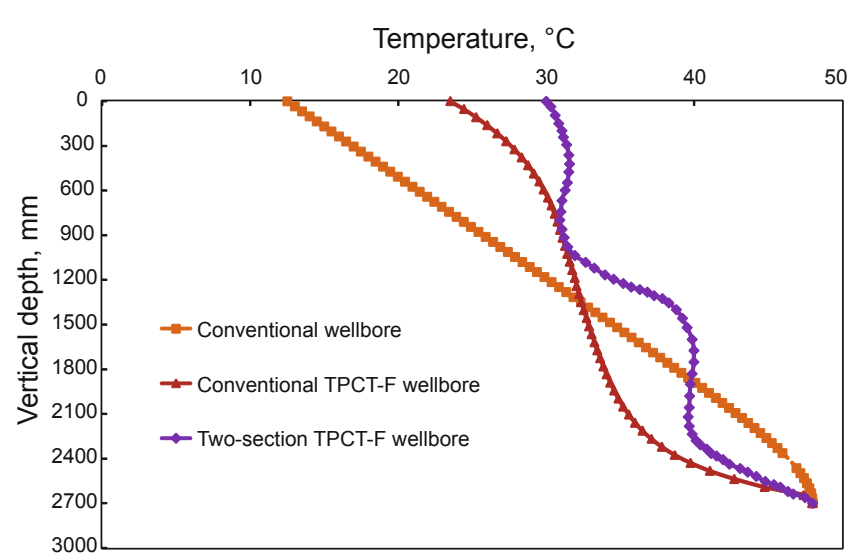

Fig. 2 Temperature distribution in the two-section TPCT-F wellbore

The heat transfer performance of the two-section TPCT in the wellbore is affected by several factors, which are dependent on each other and affect the heat transfer performance together. In the paper, the effects of the working medium, combination mode ( $\lambda$, the length ratio of the upper TPCT to the lower TPCT) and the oil flow rate on the temperature distribution in the two-section TPCT wellbore were discussed.

\subsection{Effect of the working medium on temperature distribution in the two-section TPCT wellbore}

Taking the two-section TPCT-M and combined-twosection TPCT-F-M wellbores as examples, the effect of working medium on heat transfer performance was discussed, and the experimental conditions are listed in

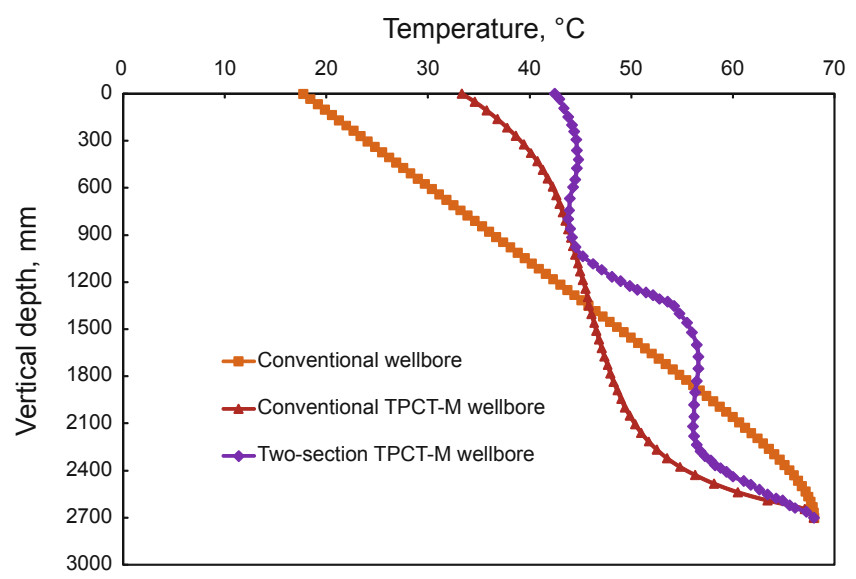

Fig. 3 Temperature distribution in the two-section TPCT-M wellbore

Table 2 and the experimental results are shown in Fig. 4. The heat transfer performance of the combined-two-section TPCT-F-M wellbore was better than that of the two-section TPCT-M wellbore, the outlet temperature of the oil in the the combined-two-section TPCT-F-M wellbore was $2.4^{\circ} \mathrm{C}$ higher than that in the two-section TPCT-M wellbore. The main reason is that best match relationship exists between working medium in TPCT and temperature field of fluid. When the oil flowed up, the oil temperature decreased. The oil temperature was $51{ }^{\circ} \mathrm{C}$ at the connection point of the upper and the lower TPCT. Freon was the best working medium in the upper TPCT, not methanol. Therefore, the heat transfer performance of the combined-two-section TPCT-F-M wellbore was better than that of the two-section TPCT-M wellbore. 
Table 2 Experimental conditions of the effect of working medium on temperature distribution

\begin{tabular}{|c|c|c|c|c|c|c|c|}
\hline \multirow[b]{2}{*}{ Wellbore } & \multicolumn{2}{|c|}{ Working medium } & \multicolumn{2}{|c|}{ Cooling water } & \multicolumn{2}{|c|}{ Oil } & \multirow{2}{*}{$\begin{array}{c}\text { Vacuum } \\
\text { degree } \\
\mathrm{kPa}\end{array}$} \\
\hline & Type & $\begin{array}{c}\text { Filling ratio } \\
\%\end{array}$ & $\begin{array}{l}\text { Temperature } \\
{ }^{\circ} \mathrm{C}\end{array}$ & $\begin{array}{c}\text { Flow rate } \\
\mathrm{L} / \mathrm{h}\end{array}$ & $\begin{array}{l}\text { Temperature } \\
{ }^{\circ} \mathrm{C}\end{array}$ & $\begin{array}{l}\text { Flow rate } \\
\mathrm{L} / \mathrm{h}\end{array}$ & \\
\hline Two-section TPCT-M & $\begin{array}{c}\text { Methanol } \\
\text { (upper and lower TPCTs) }\end{array}$ & 15 & Room temperature & 300 & 70 & 200 & 80 \\
\hline $\begin{array}{l}\text { Combined-two- } \\
\text { section TPCT-F-M }\end{array}$ & $\begin{array}{c}\text { Freon (upper TPCT) } \\
\text { Methanol (lower TPCT) }\end{array}$ & 15 & Room temperature & 300 & 70 & 200 & 80 \\
\hline
\end{tabular}

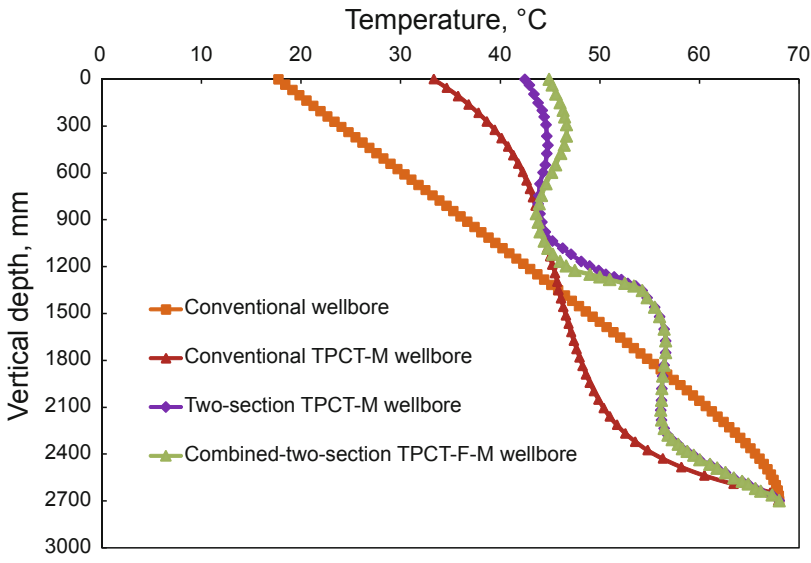

Fig. 4 The effect of the working medium on temperature distribution in the two-section TPCT wellbore

\subsection{Effect of combination mode on temperature distribution in the two-section TPCT wellbore}

Because the upper and lower TPCTs were equal in length, that is $\lambda=1$, it was impossible to experimentally analyze the effect of combination mode on temperature distribution in the two-section TPCT wellbore. Therefore, the temperature distribution in the heat absorbing section and the heat releasing section of the TPCT wellbore were calculated by Eqs. (1) and (2) (Ma et al, 2006; Wu et al, 2006). Based on the calculation result of TPCT, the effect of combination mode on temperature distribution in the two-section TPCT wellbore was analyzed.

$$
\begin{aligned}
& t_{\mathrm{f}}= {\left[t_{\mathrm{e} 0}-\frac{W}{K_{11}+K_{12}}\left(\frac{K_{11} t_{\mathrm{e} 0}+K_{12} t_{\mathrm{e}}}{W}+\frac{K_{11} G}{K_{11}+K_{12}}\right)\right] \times } \\
& \exp \left(-\frac{K_{11}+K_{12}}{W} l\right)+ \\
& \frac{W}{K_{11}+K_{12}}\left[\frac{K_{11} t_{\mathrm{e}}+K_{11}\left[t_{\mathrm{r}}-G(l+h)\right]}{W}+\frac{K_{11} G}{K_{11}+K_{12}}\right] \\
& t_{\mathrm{f}} {\left[t_{\mathrm{fw}}+\frac{W}{K_{11}+K_{12}}\left(\frac{K_{11} t_{\mathrm{fw}}-K_{12}^{\prime} t_{\mathrm{c}}}{W}+\frac{K_{11} G}{K_{11}-K_{12}^{\prime}}\right)\right] \times } \\
& \exp \left(-\frac{K_{11}-K_{12}^{\prime}}{W} l\right)+ \\
& \frac{W}{K_{11}+K_{12}}\left[\frac{K_{11}\left(t_{\mathrm{i}}+G l\right)-K_{12}^{\prime} t_{\mathrm{c}}}{W}+\frac{K_{11} G}{K_{11}+K_{12}^{\prime}}\right]
\end{aligned}
$$

where $t_{\mathrm{f}}$ is the liquid temperature in the wellbore, ${ }^{\circ} \mathrm{C} ; K_{12}^{\prime}$ is the heat transfer coefficient of the releasing section of TPCT, $\mathrm{W} / \mathrm{m}^{2} ; K_{12}$ is the heat transfer coefficient of the absorbing section of TPCT, $\mathrm{W} / \mathrm{m}^{2} ; t_{\mathrm{e} 0}$ is the liquid temperature at the bottom of TPCT, ${ }^{\circ} \mathrm{C}$; $t_{\mathrm{fw}}$ is the liquid temperature at the top of TPCT, ${ }^{\circ} \mathrm{C} ; W$ is the specific heat of the liquid in the wellbore, $\mathrm{W} / \mathrm{m} \cdot{ }^{\circ} \mathrm{C} ; K_{11}$ is the wellbore heat transfer coefficient per unit length, $\mathrm{W} / \mathrm{m}^{2} ; t_{\mathrm{e}}$ is the temperature of the TPCT wall in the absorbing section, ${ }^{\circ} \mathrm{C} ; t_{\mathrm{c}}$ is the temperature of the TPCT wall in the releasing section, ${ }^{\circ} \mathrm{C} ; l$ is the wellbore depth, $\mathrm{m} ; G$ is the geothermal gradient, ${ }^{\circ} \mathrm{C} / \mathrm{m} ; t_{\mathrm{i}}$ is the outlet temperature in TPCT, ${ }^{\circ} \mathrm{C} ; h$ is the length from bottom hole to the bottom of two-section combination TPCT; $t_{\mathrm{r}}$ is the reservoir temperature, ${ }^{\circ} \mathrm{C}$.

Under the conditions of test No. 2 in Table 2, the outlet temperatures of the oil were calculated when $\lambda$ are equal to $0.5,1,2,3,4$, respectively, and the results are shown in Fig. 5 . The results show that, the best $\lambda$ exists under the calculation conditions, that is the heat transfer performance of the combined-two-section TPCT-F-M wellbore is the best when $\lambda$ is equal to 1 , and the outlet temperature of oil is $44.9^{\circ} \mathrm{C}$. The main reason of the phenomenon is that the oil temperature in the connection point of the upper and lower TPCTs is $51{ }^{\circ} \mathrm{C}$ and Freon is more suitable for the temperature field of the oil. Therefore, the heat transfer performance of the combinedtwo-section TPCT-F-M wellbore is best when $\lambda$ is equal to 1 .

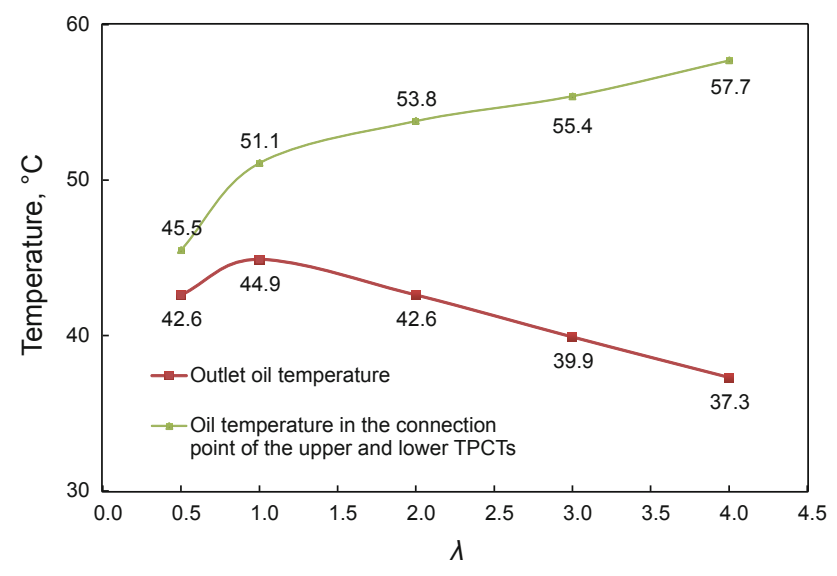

Fig. 5 Effect of combination mode on temperature distribution in the two-section TPCT wellbore

\subsection{Effect of oil flow rate on temperature distribution in the two-section TPCT wellbore}

To find out the effect of oil flow rate on temperature distribution in the two-section TPCT wellbore, two 
experiments were conducted at oil flow rate of 200 and 300 $\mathrm{L} / \mathrm{h}$, respectively. The experimental conditions are listed in Table 3 and the experimental results are shown in Fig. 6.

When the flow rate of the oil in the combined-two-section TPCT-F-M wellbore increased from $100 \mathrm{~L} / \mathrm{h}$ to $200 \mathrm{~L} / \mathrm{h}$, the outlet temperature of the oil increased by $4{ }^{\circ} \mathrm{C}$, from 40.9 ${ }^{\circ} \mathrm{C}$ to $44.9{ }^{\circ} \mathrm{C}$. However, when the flow rate of the oil in the conventional wellbore increased from $100 \mathrm{~L} / \mathrm{h}$ to $200 \mathrm{~L} / \mathrm{h}$, the outlet temperature of the oil increased only $1.7^{\circ} \mathrm{C}$, from 16.0
${ }^{\circ} \mathrm{C}$ to $17.7^{\circ} \mathrm{C}$, so the use of combined-two-section TPCT-F-M wellbore made the outlet temperature of the oil rise $2.3{ }^{\circ} \mathrm{C}$. Similarly, when the flow rate of the oil in the combined-twosection TPCT-F-M wellbore increased from $200 \mathrm{~L} / \mathrm{h}$ to 300 $\mathrm{L} / \mathrm{h}$, the outlet temperature of the oil increased by $3{ }^{\circ} \mathrm{C}$, from $44.9{ }^{\circ} \mathrm{C}$ to $47.9{ }^{\circ} \mathrm{C}$. Therefore, considering the effect of the increase in the oil flow rate on the outlet temperature of the oil, the performance of the combined-two-section TPCT-F-M wellbore is gradually weaken with increasing oil flow rate.

Table 3 Experimental conditions of effect of oil flow rate on temperature distribution

\begin{tabular}{|c|c|c|c|c|c|c|c|c|}
\hline \multirow[b]{2}{*}{ Wellbore } & \multirow[b]{2}{*}{$\lambda$} & \multicolumn{2}{|c|}{ Working medium } & \multicolumn{2}{|c|}{ Cooling water } & \multicolumn{2}{|c|}{ oil } & \multirow{2}{*}{$\begin{array}{l}\text { Vacuum degree } \\
\mathrm{kPa}\end{array}$} \\
\hline & & Type & $\begin{array}{c}\text { Filling ratio } \\
\%\end{array}$ & $\begin{array}{c}\text { Temperature } \\
{ }^{\circ} \mathrm{C}\end{array}$ & $\begin{array}{c}\text { Flow rate } \\
\mathrm{L} / \mathrm{h}\end{array}$ & $\begin{array}{c}\text { Temperature } \\
{ }^{\circ} \mathrm{C}\end{array}$ & $\begin{array}{c}\text { Flow rate } \\
\mathrm{L} / \mathrm{h}\end{array}$ & \\
\hline $\begin{array}{c}\text { Combined-two-section } \\
\text { TPCT-F-M }\end{array}$ & 1 & $\begin{array}{c}\text { Freon (upper TPCT) } \\
\text { Methanol (lower TPCT) }\end{array}$ & 15 & Room temperature & 300 & 70 & 100 & 80 \\
\hline $\begin{array}{c}\text { Combined-two-section } \\
\text { TPCT-F-M }\end{array}$ & 1 & $\begin{array}{c}\text { Freon (upper ТРСТ) } \\
\text { Methanol (lower TPCT) }\end{array}$ & 15 & Room temperature & 300 & 70 & 200 & 80 \\
\hline $\begin{array}{c}\text { Combined-two-section } \\
\text { TPCT-F-M }\end{array}$ & 1 & $\begin{array}{c}\text { Freon (upper ТРСТ) } \\
\text { Methanol (lower TPCT) }\end{array}$ & 15 & Room temperature & 300 & 70 & 300 & 80 \\
\hline
\end{tabular}

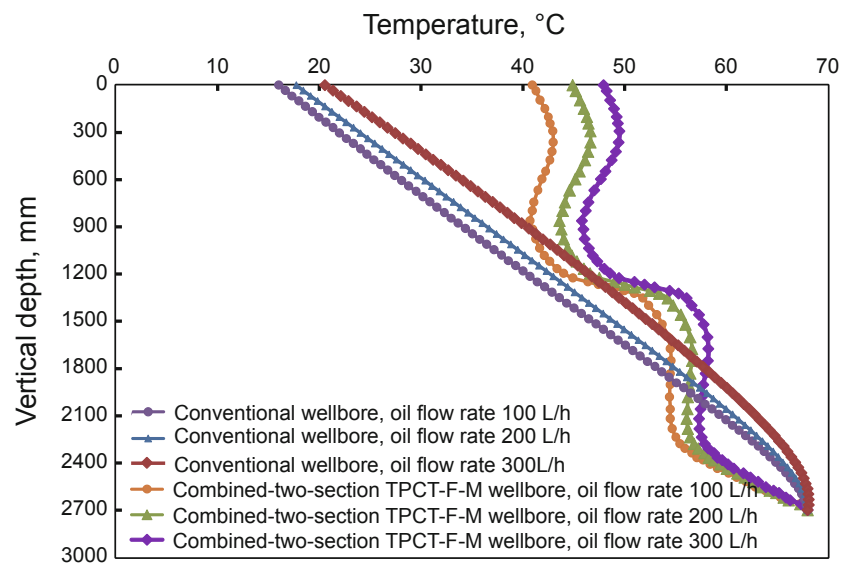

Fig. 6 Effect of oil flow rate on temperature distribution in the two-section TPCT wellbore

For the combined-two-section TPCT-F-M wellbore (Freon filled in the upper TPCT and methanol filled in the lower TPCT), when the oil temperature at the connection point of the upper and lower TPCTs is about $50{ }^{\circ} \mathrm{C}$, this combination mode is optimal. The optimal combination mode was calculated to be when the oil flow rate was 100 and $300 \mathrm{~L} /$ $\mathrm{h}$, respectively, and the results are shown in Fig. 7 . The best combination mode $\lambda$ is equal to 1.5 when the oil flow rate is $100 \mathrm{~L} / \mathrm{h}$, however $\lambda$ is equal to 0.5 when the oil flow rate is $300 \mathrm{~L} / \mathrm{h}$. This shows that the oil flow rate has an effect on the combination mode, that is, with an increase in the oil flow rate, the point at which the oil temperature is $50{ }^{\circ} \mathrm{C}$ moves upward gradually, so reducing the length of the upper TPCT may achieve the best combination mode.

\section{Conclusions}

The two-section TPCT wellbore overcomes shortcomings of the conventional TPCT wellbore and its heat transfer performance is better than that of the conventional TPCT wellbore. The heat transfer performance of the two-

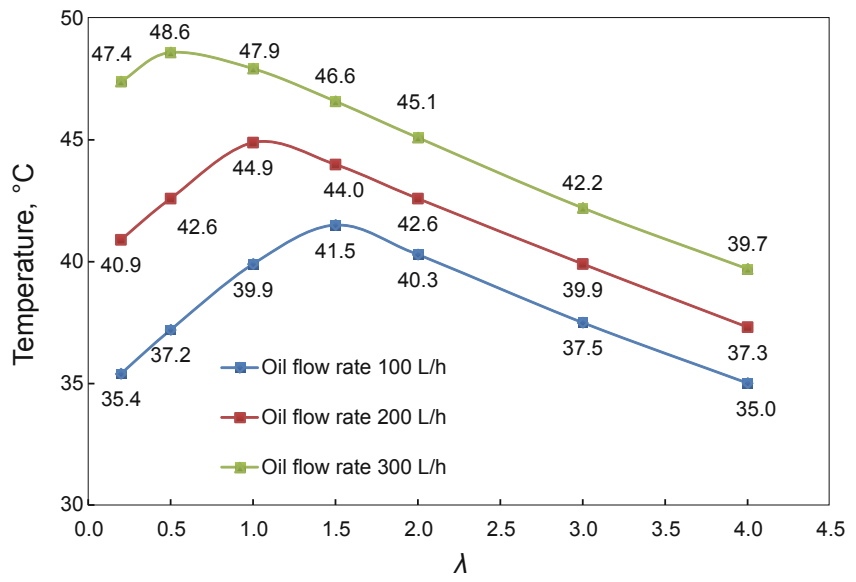

Fig. 7 Effect of the oil flow rate on combination mode

section TPCT wellbore is affected by the working medium, combination mode, oil flow rate, etc. The heat transfer performance of the combined-two-section TPCT-F-M wellbore (the working media that match with the temperature fields of oil in the upper and lower TPCTs) is better than that of the two-section TPCT wellbore filled with the same working medium in the upper and lower TPCTs. This reflects the characteristic of the match between the working medium and the temperature field. Interdependence exists between combination mode and flow rate of the oil, that is, the best combination mode is different when the oil flow rate changes, which affects the heat transfer performance of the two-section TPCT wellbore together. Under the experimental conditions, the two-section combined TPCT wellbore with the same length of upper and lower TPCTs, which are filled with Freon and methanol, respectively, have the best heat transfer performance when the oil flow rate is $200 \mathrm{~L} / \mathrm{h}$.

\section{Acknowledgements}

The authors are grateful for the financial support from 
the National Natural Science Foundation of China (No. 50674096) and PetroChina Scientific \& Technological Risk Innovation Project (No. 060511-2-1).

\section{References}

Aljundi I H. Energy and exergy analysis of a power plant in Jordan. Applied Thermal Engineering. 2009. 29: 324-328

Behrooz M Z and Ahad A. First and second laws analysis of the heat pipe/ejector refrigeration cycle. Energy. 2010. 35: 3307-3314

Cazarez-Candia O and Vásquez-Cruz M A. Prediction of pressure, temperature, and velocity distribution of two-phase flow in oil wells. Journal of Petroleum Science and Engineering. 2005. 46(3): 195-208

Fan R, Jiang Y Q, Yao Y, et al. A study of the performance of a geothermal heat exchanger under coupled heat conduction and groundwater advection. Energy. 2007. 32: 2199-2209

Huminic G, Huminic A, Morjan I and Dumitrache F. Experimental study of the thermal performance of thermosyphon heat pipe using iron oxide nanoparticles. International Journal of Heat and Mass Transfer. 2011. 54(1-3): 656-661

Jaehnig D and Isaksson C. Solar integration, five easy ways to incorporate solar thermal into conventional heating systems. Renewable Energy World. 2006. 6: 66-72

Jouhara H. Economic assessment of the benefits of wraparound heat pipes in ventilation processes for hot and humid climates. International Journal of Low-Carbon Technologies. 2009. 4(1): 52-60

Jouhara H, Anastasov V and Khamis I. Potential of heat pipe technology in nuclear seawater desalination. Desalination. 2009. 249(3): 10551061

Jouhara H and Robinson A J. An experimental study of small-diameter wickless heat pipes operating in the temperature range $200{ }^{\circ} \mathrm{C}$ to 450 ${ }^{\circ}$ C. Heat Transfer Engineering. 2009. 30(13): 1041-1048

Jouhara $\mathrm{H}$ and Meskimmon. Experimental investigation of wraparound loop heat pipe heat exchanger used in energy efficient air handling units. Energy. 2010. 35: 4592-4599

Khamis I, Jouhara H and Anastasov V. Heat pipes as an extra measure to eliminate radioactive contamination in nuclear seawater desalination. Desalination and Water Treatment. 2010. 13: 82-87

Khandekar S, Joshi Y M and Mehta B. Thermal performance of closed two-phase thermosyphon using nanofluids. International Journal of Thermal Science. 2008. 47(6): 659-667

$\mathrm{Ma} \mathrm{C} \mathrm{H,} \mathrm{Wu} \mathrm{X} \mathrm{D} \mathrm{and} \mathrm{Shi} \mathrm{C} \mathrm{B.} \mathrm{Theoretical} \mathrm{research} \mathrm{for} \mathrm{improving}$ temperature distribution of fluid in wellbores using heat pipes. Acta Petrolei Sinica. 2006. 27(1): 114-118 (in Chinese)

Misheck G M, Huang X and Gu J J. Influence of wick characteristics on heat pipe performance. International Journal of Energy Research. 2006. 30: 489-499

Paramatthanuwat T, Boothaisong S, Rittidech S, et al. Heat transfer characteristics of a two-phase closed thermosyphon using de ionized water mixed with silver nano. Heat and Mass Transfer. 2010. 46(3):
281-285

Pridasawas W and Lundqvist P. An exergy analysis of a solar-driven ejector refrigeration system. International Journal of Solar Energy. 2008. 76: 369-379

Rahimi M, Asgary K and Jesri S. Thermal characteristics of a resurfaced condenser and evaporator closed two-phase thermosyphon. International Communications in Heat and Mass Transfer. 2010. 37(6): 703-710

Shanbedi M, Heris S Z, Baniadam M, et al. Investigation of heat-transfer characterization of EDA-MWCNT/DI-water nanofluid in a twophase closed thermosyphon. Industrial \& Engineering Chemistry Research. 2012. 51: 1423-1428

Shi H and Homes J A. Drift-flux modeling of multiphase flow in wellbores. Paper SPE84228 presented at the 2003 SPE Annual Technical Conference and Exhibition, 5-8 October 2003, Denver, USA

Singh R, Masataka M, Mashiko K, et al. Heat pipe based cold energy storage systems for datacenter energy conservation. Energy. 2011. 36: 2802-2811

Sobhan C B, Rag R L and Peterson G P. A review and comparative study of the investigations on micro heat pipes. International Journal of Energy Research. 2007. 31: 664-688

Tian S F and Finger J T. Advanced geothermal wellbore hydraulics model. Journal of Energy Resources Technology. 2000. 122(3): 142146

Wu X D, Ma C H, Shi C B, et al. The application of TPCT heat transfer in steam huff and puff wells. Oil Drilling \& Production Technology. 2006. 28(1): 60-63 (in Chinese)

Wu X D, Zhang Y F, Han G Q, et al. Research on laboratory and field experiments of two-phase closed thermosyphon in wellbores. Journal of Southwest Petroleum University (Science \& Technology Edition). 2008. 30(1): 140-142 (in Chinese)

Yau Y H. Analysis of enthalpy change with/without a heat pipe heat exchanger in a tropical air conditioning system. International Journal of Energy Research. 2006. 30: 1251-1263

Wang Z Y and Zhao X D. Analytical study of the heat transfer limits of a novel loop heat pipe system. International Journal of Energy Research. 2011. 35: 404-414

Zhang Y F, Wu X D and Li W C. Feasibility of two-phase closed thermosyphon heating method. Petroleum Exploration and Development. 2007. 34(4): 483-487 (in Chinese)

Zhang Y F, Wu X D, Tian S C, et al. Research on two-phase closed thermosyphon to improve fluid temperature distribution in wellbores. Petroleum Science and Technology. 2010. 28: 1884-1894

Zhang Y F, Wu X D, Zhang Y M, et al. Two-phase closed thermosyphon (TPCT) decreases heat loss of liquid within heavy oil wellbores. Petroleum Exploration and Development. 2011. 38(2): 228-232 (in Chinese)

(Edited by Sun Yanhua) 